International Journal of Pure and Applied Mathematics

Volume 87 No. 3 2013, 431-441

ISSN: 1311-8080 (printed version); ISSN: 1314-3395 (on-line version)

url: http://www.ijpam.eu

doi: http://dx.doi.org/10.12732/ijpam.v87i3.7

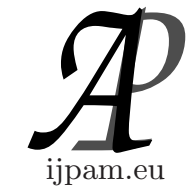

\title{
CONE METRIC SPACES AND COMMON FIXED POINT THEOREMS FOR CERTAIN CONTRACTIVE MAPPINGS
}

\author{
A.K. Dubey ${ }^{1}$, Reena Shukla ${ }^{2}$, R.P. Dubey ${ }^{3}$ \\ ${ }^{1}$ Department of Mathematics \\ Bhilai Institute of Technology \\ Bhilai House, Durg, 491001, INDIA \\ ${ }^{2,3}$ Department of Mathematics \\ Dr. C.V. Raman University \\ Bilaspur (C.G.), INDIA
}

\begin{abstract}
The purpose of this paper is to establish some common fixed point results for two Banach pairs of mappings which satisfy T-Reich and TRhoades contraction conditions in cone metric spaces without the assumption of normality condition of the cone.
\end{abstract}

AMS Subject Classification: 47H10, 54H25

Key Words: fixed point, cone metric spaces, contraction mapping

\section{Introduction and Preliminary Notes}

Recently, Huang and Zhang [1] introduce the notion of cone metric spaces. He replaced real number system by ordered Banach space. He also gave the condition in the setting of cone metric spaces. These authors also described the convergence of sequences in the cone metric spaces and introduce the corresponding notion of completeness. Subsequently, many authors have generalized the results of Huang and Zhang and have studied fixed point theorems for normal and non-normal cones, see for instance [4], [8], [10], [11], [13], [14], etc.

In 2009, A. Beiranvand [2] et al introduced new classes of contractive functions T-contraction and T-contractive mappings and then they established and

Received: May 27, 2013

(c) 2013 Academic Publications, Ltd.

$\S$ Correspondence author 
extended the Banach contraction principle. J.R. Morales and the E. Rojas [5], [6] obtained sufficient conditions for the existence of a unique fixed point of TKannan contractive, T-Zamfirescu, T-contractive mappings on complete cone metric spaces.

In [8], authors have proved some common fixed point theorems for a $\mathrm{Ba}$ nach pair of mappings satisfying T-Hardy Rogers type contraction condition in cone metric spaces. In sequel M. Ozturk and M. Basarir [3] proved some common fixed point theorems for f-contraction mapping in cone metric spaces without the assumption of normality condition of the cone. Subrahmanyam [9] introduced Banach operator of type $k$. Recently Chen and Li [7] extended the concept of Banach operator of type $k$ to Banach operator pair and proved various best approximation results using common fixed point theorems for $\mathrm{f}$ nonexpansive mappings.

The aim of this paper is to prove common fixed point theorems for two Banach pairs of mappings which satisfy T-Reich and T-Rhoades contraction conditions in cone metric spaces without the assumption of normality condition of the cone.

First, we recall some standard definitions and other results that will be needed in the sequel.

Definition 1.1. A self mapping $T$ of a metric space $(X, d)$ is said to be a contraction mapping, if there exists a real number $0 \leqslant k<1$ such that for all $x, y \in X$,

$$
d(T x, T y) \leqslant k d(x, y) .
$$

Definition 1.2. (see [2]) Let $T$ and $f$ be two self-mappings of a metric space $(X, d)$. The self mapping $f$ of $X$ is said to be T-contraction, if there exists a real number $0 \leqslant k<1$ such that

$$
d(T f x, T f y) \leqslant k d(T x, T y),
$$

for all $x, y \in X$.

If $T=I$, the identity mapping, Definition 1.2 reduces to Banach contraction mapping.

Example 1. Let $X=[0, \infty)$ be with the usual metric. Let define two mappings $T, f: X \rightarrow X$ as

$$
\begin{aligned}
& f x=\beta x, \quad \beta>1, \\
& T x=\frac{\propto}{x^{2}}, \quad \propto \in R .
\end{aligned}
$$


It is clear that, $f$ is not contraction but $f$ is T-contraction, since,

$$
d(T f x, T f y)=\left|\frac{\propto}{\beta^{2} x^{2}}-\frac{\propto}{\beta^{2} y^{2}}\right|=\frac{1}{\beta^{2}}|T x-T y|
$$

Definition 1.3. (see [2] Let $T$ be a self mapping of a metric space $(X, d)$. Then:

(i) A mapping $T$ is said to be sequentially convergent, if the sequence $\left\{y_{n}\right\}$ in $X$ is convergent whenever $\left\{T y_{n}\right\}$ is convergent.

(ii) A mapping $T$ is said to be subsequentially convergent, if $\left\{y_{n}\right\}$ has a convergent subsequence whenever $\left\{T y_{n}\right\}$ is convergent.

Definition 1.4. (see [9]) Let $T$ be a self mapping of a normed space $X$. Then $T$ is called a Banach operator of type $k$ if

$$
\left\|T^{2} x-T x\right\| \leqslant k\|T x-x\|,
$$

for some $k \geqslant 0$ and for all $x \in X$.

This concept was introduced by Subrahmanyam [9] then Chen and Li [7] extended this as following.

Definition 1.5. (see [7]) Let $T$ and $f$ be two self mappings of a non-empty subset $M$ of a normed linear space $X$. Then $(T, f)$ is a Banach operator pair, if any one of the following conditions is satisfied:

(i) $T[F(f)] \subseteq F(f)$, i.e. $F(f)$ is T-invariant;

(ii) $f T x=T x$ for each $x \in F(f)$;

(iii) $f T x=T f x$ for each $x \in F(f)$;

(iv) $\|T f x-f x\| \leqslant k\|f x-x\|$ for some $k \geqslant 0$.

Definition 1.6. (see [1]) Let $E$ be a real Banach space and $P$ a subset of E. $P$ is called a cone if and only if:

(i) $P$ is closed, non-empty and $P \neq\{0\}$;

(ii) $a x+b y \in P$ for all $x, y \in P$ and non-negative real numbers $a, b$;

(iii) $x \in P$ and $-x \in P \Rightarrow x=0 \Leftrightarrow P \cap(-P)=\{0\}$.

Given a cone $P \subset E$, a partial ordering is defined as $\leqslant$ on $E$ with respect to $P$ by $x \leqslant y$ if and only if $y-x \in P$. It is denoted as $x \ll y$ will stand for 
$y-x \in$ int $P$ where int $P$ denotes the interior of $P$. The cone $P$ is called normal if there is a number $K>0$ such that for all $x, y \in E$,

$$
0 \leqslant x \leqslant y \text { implies }\|x\| \leqslant K\|y\| .
$$

The least positive number K satisfying (1.3) is called normal constant of $P$.

Definition 1.7. (see [1]) Let $X$ be a non-empty set. Suppose $E$ is a real Banach space, $P$ is a cone with int $P \neq \phi$ and $\leqslant$ is a partial ordering with respect to $P$. If the mapping $d: X \times X \rightarrow E$ satisfies:

(i) $0 \leqslant d(x, y)$ for all $x, y \in X$ and $d(x, y)=0$ if and only if $x=y$;

(ii) $d(x, y)=d(y, x)$ for all $x, y \in X$;

(iii) $d(x, y) \leqslant d(x, z)+d(z, y)$ for all $x, y, z \in X$.

Then $d$ is called a cone metric on $X$ and $(X, d)$ is called a cone metric space.

Definition 1.8. (see [5]) Let $(X, d)$ be a cone metric space and $\left\{x_{n}\right\}$ be a sequence in $X$. Then:

(i) $\left\{x_{n}\right\}$ converges to $x \in X$, if for every $c \in E$ with $0 \ll c$, there is $n_{o} \in N$, the set of all natural numbers such that for all $n \geqslant n_{o}, d\left(x_{n}, x\right) \ll c$. It is denoted by $\lim _{n \rightarrow \infty} x_{n}=x$ or $x_{n} \rightarrow x,(n \rightarrow \infty)$;

(ii) If for any $c \in E$, there is a number $n_{o} \in N$ such that for all $m, n \geqslant$ $n_{o}, d\left(x_{n}, x_{m}\right) \ll c$, then $\left\{x_{n}\right\}$ is called a Cauchy sequence in $X ;(X, d)$ is a complete cone metric space, if every Cauchy seuence in $X$ is convergent;

A self mapping $T: X \rightarrow X$ is said to be continuous at a point $x \in X$, if $\lim _{n \rightarrow \infty} x_{n}=x$ implies that $\lim _{n \rightarrow \infty} T x_{n}=T x$ for every $\left\{x_{n}\right\}$ in $X$.

Lemma 1.1. (see [11]) Let $(X, d)$ be a cone metric space, $u, v, w \in X$ Then:

(i) If $u \ll v$ and $v \ll w$, then $u \ll w$;

(ii) If $u \leqslant v$ and $v \ll w$, then $u \ll w$;

(iii) If $0 \leqslant u \ll c$ for each $c \in$ int $P$, then $u=0$;

(iv) If $c \in$ int $P, 0 \leqslant a_{n}$ and $a_{n} \rightarrow 0$,then there exists $n_{o}$ such that for all $n>n_{o}$, it follows that $a_{n} \ll c$. 


\section{Main Results}

First, we give definitions of T-Reich contractive and T-Rhoades contractive mappings on cone metric spaces which are based on the ideas of Morales and Rojas [5].

Definition 2.1. Let $(X, d)$ be a cone metric space and $T, S: X \rightarrow X$ two functions:

(i) A mapping $S$ is said to be T-Reich contraction, if there is $a+b+c<1$ such that

$$
d(T S x, T S y) \leqslant a d(T x, T S x)+b d(T y, T S y)+c d(T x, T y)
$$

for all $x, y \in X$ and $a, b, c \geqslant 0$.

(ii) A mapping $S$ is said to be T-Rhoades contraction, if there is $a+b+c<1$ such that

$$
d(T S x, T S y) \leqslant a d(T x, T S y)+b d(T y, T S x)+c d(T x, T y)
$$

for all $x, y \in X$ and $a, b, c \geqslant 0$.

Theorem 2.1. Let $T, f$ and $g$ be three continuous self mappings of a complete cone metric space $(X, d)$. Assume that $T$ is a injective mapping. If the mappings $T, f$ and $g$ satisfy

$$
d(T f x, T g y) \leqslant a_{1} d(T x, T f x)+a_{2} d(T y, T g y)+a_{3} d(T x, T y),
$$

for all $x, y \in X$ where $a_{i}, i=1,2,3$ are all non-negative constants such that $a_{1}+a_{2}+a_{3}<1$ then $f$ and $g$ have a unique common fixed point in $X$. Moreover, if $(T, f)$ and $(T, g)$ are Banach pairs, then $T, f$ and $g$ have a unique common fixed point in $X$.

Proof. Let $x_{o} \in X$ as an arbitrary element and define the sequences $x_{2 n+1}=$ $f x_{2 n}$ and $x_{2 n+2}=g x_{2 n+1}$ for each $n=0,1,2, \ldots, \infty$. Then, by using $(2.3)$ and triangle inequality

$$
\begin{aligned}
d\left(T x_{2 n+1}, T x_{2 n}\right)= & d\left(T f x_{2 n}, T g x_{2 n-1}\right) \\
\leqslant & a_{1} d\left(T x_{2 n}, T f x_{2 n}\right)+a_{2} d\left(T x_{2 n-1}, T g x_{2 n-1}\right) \\
& +a_{3} d\left(T x_{2 n}, T x_{2 n-1}\right) \\
= & a_{1} d\left(T x_{2 n}, T x_{2 n+1}\right)+a_{2} d\left(T x_{2 n-1}, T x_{2 n}\right) \\
& +a_{3} d\left(T x_{2 n}, T x_{2 n-1}\right)\left(1-a_{1}\right) d\left(T x_{2 n+1} T x_{2 n}\right)
\end{aligned}
$$




$$
\begin{aligned}
\leqslant & \left(a_{2}+a_{3}\right) d\left(T x_{2 n}, T x_{2 n-1}\right) \\
& d\left(T x_{2 n+1}, T x_{2 n}\right) \\
= & \frac{a_{2}+a_{3}}{1-a_{1}} d\left(T x_{2 n}, T x_{2 n-1}\right) .
\end{aligned}
$$

Similarly:

$$
\begin{aligned}
d\left(T x_{2 n+3}, T x_{2 n+2}\right)= & d\left(T f x_{2 n+2}, T g x_{2 n+1}\right) \\
\leqslant & a_{1} d\left(T x_{2 n+2}, T f x_{2 n+2}\right)+a_{2} d\left(T x_{2 n+1}, T g x_{2 n+1}\right) \\
& +a_{3} d\left(T x_{2 n+2}, T x_{2 n+1}\right) \\
= & a_{1} d\left(T x_{2 n+2}, T x_{2 n+3}\right)+a_{2} d\left(T x_{2 n+1}, T x_{2 n+2}\right) \\
& +a_{3} d\left(T x_{2 n+2}, T x_{2 n+1}\right), \\
d\left(T x_{2 n+3}, T\right. & \left.x_{2 n+2}\right)=\frac{a_{2}+a_{3}}{1-a_{1}} d\left(T x_{2 n+2}, T x_{2 n+1}\right) .
\end{aligned}
$$

Thus

$$
d\left(T x_{n+1}, T x_{n}\right) \leqslant \lambda d\left(T x_{n}, T x_{n-1}\right) \leqslant \cdots \leqslant \lambda^{n} d\left(T x_{1}, T x_{o}\right),
$$

for all $n \geqslant 0$, where $\lambda=\frac{a_{2}+a_{3}}{1-a_{1}}<1$.

Now for $n>m$ we have

$$
\begin{aligned}
d\left(T x_{n}, T x_{m}\right) & \leqslant d\left(T x_{n}, T x_{n-1}\right)+d\left(T x_{n-1}, T x_{n-2}\right)+\cdots+d\left(T x_{m+1}, T x_{m}\right) \\
& \leqslant\left(\lambda^{n-1}+\lambda^{n-2}+\cdots+\lambda^{m}\right) d\left(T x_{1}, T x_{o}\right) \\
& \leqslant \frac{\lambda^{m}}{1-\lambda} d\left(T x_{1}, T x_{o}\right) .
\end{aligned}
$$

Let $0 \ll c$ be given. Choose $\delta>0$ such that $c+N_{\delta}(0) \subseteq P$, where

$$
N_{\delta}(0)=\{y \in E:\|y\|<\delta\} .
$$

Also, choose a natural number $N_{1}$ such that $\frac{\lambda^{m}}{1-\lambda} d\left(T x_{1}, T x_{o}\right) \in N_{\delta}(0)$, for all $m \geqslant N_{1}$. Then

$$
\frac{\lambda^{m}}{1-\lambda} d\left(T x_{1}, T x_{o}\right) \ll c, \text { for all } m \geqslant N_{1} \text {. }
$$

Thus

$$
d\left(T x_{n}, T x_{m}\right) \leqslant \frac{\lambda^{m}}{1-\lambda} d\left(T x_{1}, T x_{o}\right)
$$

and

$$
\frac{\lambda^{m}}{1-\lambda} d\left(T x_{1}, T x_{o}\right) \ll c
$$


for all $m>n$. Then we get $d\left(T x_{n}, T x_{m}\right) \ll c$ for all $n>m$. Therefore, $\left\{T x_{n}\right\}$ is a Cauchy sequence in $(X, d)$. As $X$ is complete, there exists $z \in X$ such that $\lim _{n \rightarrow \infty} T x_{n}=z$.

Since $T$ is sub-sequentially convergent, $\left\{x_{n}\right\}$ has a convergent subsequence $\left\{x_{m}\right\}$ such that $\lim _{m \rightarrow \infty} x_{m}=u$. As $T$ is continuous

$$
\lim _{m \rightarrow \infty} T x_{m}=T u
$$

By the uniqueness of the limit, $z=T u$. Since $f$ and $g$ are continuous, $\lim _{m \rightarrow \infty} g x_{m}=g u$ and $\lim _{m \rightarrow \infty} f x_{m}=f u$. Agains since $T$ is continuous, $\lim _{m \rightarrow \infty} T g x_{m}=$ Tgu and $\lim _{m \rightarrow \infty}$ Tf $x_{m}=T f u$.

Therefore, if $m$ is odd, then

$$
\lim _{n \rightarrow \infty} \operatorname{Tg} x_{2 n+1}=\operatorname{Tg} u
$$

Choose a natural number $N_{2}$ such that

$$
d\left(T x_{2 n+1}, T u\right) \ll\left[\frac{c}{2}\left(\frac{a_{2}+a_{3}}{1-a_{1}}\right)\right]
$$

for all $n \geqslant N_{2}$.

Now consider

$$
\begin{aligned}
d(T g u, T u) \leqslant & d\left(T g u, T x_{2 n+1}\right)+d\left(T x_{2 n+1}, T u\right) \\
= & d\left(T g u, T f x_{2 n}\right)+d\left(T f x_{2 n}, T u\right) \\
\leqslant & a_{1} d(T u, T g u)+a_{2} d\left(T x_{2 n}, T f x_{2 n}\right) \\
& +a_{3} d\left(T u, T x_{2 n}\right)+d\left(T x_{2 n+1}, T u\right) \\
= & a_{1} d(T u, T g u)+a_{2} d\left(T x_{2 n}, T x_{2 n+1}\right) \\
& +a_{3} d\left(T u, T x_{2 n}\right)+d\left(T x_{2 n+1}, T u\right) .
\end{aligned}
$$

So

$$
d(T u, T g u) \leqslant\left(\frac{a_{2}+a_{3}}{1-a_{1}}\right) d\left(T x_{2 n}, T u\right)+\left(\frac{1+a_{2}}{1-a_{1}}\right) d\left(T u, T x_{2 n+1}\right) \ll c,
$$

for all $n \geqslant N_{2}$. Therefore, $d(T u, T g u) \ll \frac{c}{i}$ for all $i \geqslant 1$. Hence, $\frac{c}{i}-d(T u, T g u) \in$ $P$ for all $i \geqslant 1$. Since $P$ is closed, $-d(T u, T g u) \in P$ and so $d(T u, T g u)=0$. Hence $T u=T g u$. As $T$ is injective, $u=g u$. Thus $u$ in the fixed point of $g$. And if $m$ is even, then we have

$$
\lim _{n \rightarrow \infty} T f x_{2 n}=T f u
$$


Now, by using (2.3) and triangle inequality, we have

$$
d(T u, T f u) \leqslant\left(\frac{a_{2}+a_{3}}{1-a_{1}}\right) d\left(T x_{2 n+1}, T u\right)+\left(\frac{1+a_{2}}{1-a_{1}}\right) d\left(T u, T x_{2 n+2}\right) \ll c,
$$

for all $n \geqslant N_{2}$. Therefore, $d(T u, T f u) \ll \frac{c}{i}$ for all $i \geqslant 1$. Hence, $\frac{c}{i}-d(T u, T f u) \in$ $P$ for all $i \geqslant 1$. Since $P$ is closed, $-d(T u, T f u) \in P$ and so $d(T u, T f u)=0$. Hence $T u=T f u$. As $T$ is injective, $u=f u$. Thus $u$ in the fixed point of $f$ too.

For the uniqueness suppose that $u^{*}$ is another common fixed point of $f$ amd $g$,

$$
\begin{aligned}
& d\left(T u, T u^{*}\right)= d\left(T f u, T g u^{*}\right) \\
& \leqslant a_{1} d(T u, T f u)+a_{2} d\left(T u^{*}, T g u^{*}\right) \\
&+a_{3} d\left(T u, T u^{*}\right), \\
& d\left(T u, T u^{*}\right) \leqslant\left(a_{1}+a_{2}+a_{3}\right) d\left(T u, T u^{*}\right) .
\end{aligned}
$$

Since $a_{1}+a_{2}+a_{3}<1, d\left(T u, T u^{*}\right)=0$ which implies that $T u=T u^{*}$. We know that $T$ is injective, $u=u^{*}$ is the unique common fixed point of $f$ and $g$. Since we have assumed that $\{T, f\}$ and $\{T, g\}$ are Banach pairs; $\{T, f\}$ and $\{T, g\}$ commutes at the fixed point of $f$ and $g$, respectively. This implies that $T f u=f T u$ for $u \in F(f)$. So $T u=f T u$ which gives that $T u$ is another fixed point of $f$. It is true for $g$, too. By the uniquesness of fixed point of $f, T u=u$. Hence $u=T u=f u=g u, u$ is unique common fixed point of $T, f$ and $g$ in $X$.

Theorem 2.2. Let $T, f$ and $g$ be three continuous self mappings of a complete cone metric space $(X, d)$. Assume that $T$ is a injective mapping. If the mappings $T, f$ and $g$ satisfy

$$
d(T f x, T g y) \leqslant a_{1} d(T x, T g y)+a_{2} d(T y, T f x)+a_{3} d(T x, T y)
$$

for all $x, y \in X$ where $a_{i}, i=1,2,3$ are all non-negative constants such that $a_{1}+a_{2}+a_{3}<1$ and $a_{1}=a_{2}$ then $f$ and $g$ have a unique common fixed point in $X$. Moreover, if $(T, f)$ and $(T, g)$ are Banach pairs, then $T, f$ and $g$ have a unique common fixed point in $X$.

Proof. Let $x_{o} \in X$ as an arbitrary element and define the sequences $x_{2 n+1}=$ $f x_{2 n}$ and $x_{2 n+2}=g x_{2 n+1}$ for each $n=0,1,2, \ldots, \infty$. Then by using (2.4) and triangle inequality

$$
\begin{aligned}
d\left(T x_{2 n+1,} T x_{2 n}\right) & =d\left(T f x_{2 n}, T g x_{2 n-1}\right) \\
& \leqslant a_{1} d\left(T x_{2 n}, T g x_{2 n-1}\right)+a_{2} d\left(T x_{2 n-1}, T f x_{2 n}\right)
\end{aligned}
$$




$$
\begin{aligned}
& +a_{3} d\left(T x_{2 n}, T x_{2 n-1}\right) \\
= & a_{1} d\left(T x_{2 n}, T x_{2 n}\right)+a_{2} d\left(T x_{2 n-1}, T x_{2 n+1}\right) \\
& +a_{3} d\left(T x_{2 n}, T x_{2 n-1}\right) \\
\leqslant & a_{2}\left[d\left(T x_{2 n-1}, T x_{2 n}\right)+d\left(T x_{2 n}, T x_{2 n+1}\right)\right] \\
& +a_{3} d\left(T x_{2 n}, T x_{2 n-1}\right), \\
d\left(T x_{2 n+1}, T x_{2 n}\right) \leqslant a_{2} d\left(T x_{2 n+1}, T x_{2 n}\right)+\left(a_{2}+a_{3}\right) d\left(T x_{2 n}, T x_{2 n-1}\right), & \\
d\left(T x_{2 n+1},\right. & \left.T x_{2 n}\right)=\frac{a_{2}+a_{3}}{1-a_{2}} d\left(T x_{2 n}, T x_{2 n-1}\right) .
\end{aligned}
$$

Similarly,

$$
\begin{aligned}
d\left(T x_{2 n+3}, T x_{2 n+2}\right)= & d\left(T f x_{2 n+2}, T g x_{2 n+1}\right) \\
\leqslant & a_{1} d\left(T x_{2 n+2}, T g x_{2 n+1}\right)+a_{2} d\left(T x_{2 n+1}, T f x_{2 n+2}\right) \\
& +a_{3} d\left(T x_{2 n+2}, T x_{2 n+1}\right) \\
= & a_{1} d\left(T x_{2 n+2}, T x_{2 n+2}\right)+a_{2} d\left(T x_{2 n+1}, T x_{2 n+3}\right) \\
& +a_{3} d\left(T x_{2 n+2}, T x_{2 n+1}\right) \\
\leqslant & a_{2}\left[d\left(T x_{2 n+1}, T x_{2 n+2}\right)+d\left(T x_{2 n+2}, T x_{2 n+3}\right)\right] \\
& +a_{3} d\left(T x_{2 n+2}, T x_{2 n+1}\right), \\
d\left(T x_{2 n+3},\right. & \left.T x_{2 n+2}\right)=\frac{a_{2}+a_{3}}{1-a_{2}} d\left(T x_{2 n+2}, T x_{2 n+1}\right) .
\end{aligned}
$$

Thus

$$
d\left(T x_{n+1}, T x_{n}\right) \leqslant \lambda d\left(T x_{n}, T x_{n-1}\right) \leqslant \cdots \leqslant \lambda^{n} d\left(T x_{1}, T x_{o}\right),
$$

for all $n \geqslant 0$ where $\lambda=\frac{a_{2}+a_{3}}{1-a_{2}}<1$.

Now for $n>m$ we have

$$
\begin{aligned}
d\left(T x_{n}, T x_{m}\right) & \leqslant d\left(T x_{n}, T x_{n-1}\right)+d\left(T x_{n-1}, T x_{n-2}\right)+\cdots+d\left(T x_{m+1}, T x_{m}\right) \\
& \leqslant\left(\lambda^{n-1}+\lambda^{n-2}+\cdots+\lambda^{m}\right) d\left(T x_{1}, T x_{0}\right) \\
& \leqslant \frac{\lambda^{m}}{1-\lambda} d\left(T x_{1}, T x_{o}\right) .
\end{aligned}
$$

Let $0 \ll c$ be given. Choose $\delta>0$ such that $c+N_{\delta}(0) \subseteq P$, where $N_{\delta}(0)=$ $\{y \in E:\|y\|<\delta\}$.

Also, choose a natural number $N_{1}$ such that $\frac{\lambda^{m}}{1-\lambda} d\left(T x_{1}, T x_{0}\right) \in N_{\delta}(0)$, for all $m \geqslant N_{1}$. Then $\frac{\lambda^{m}}{1-\lambda} d\left(T x_{1}, T x_{0}\right) \ll c$, for all $m \geqslant N_{1}$. Thus

$$
d\left(T x_{n}, T x_{m}\right) \leqslant \frac{\lambda^{m}}{1-\lambda} d\left(T x_{1}, T x_{0}\right)
$$


and

$$
\frac{\lambda^{m}}{1-\lambda} d\left(T x_{1}, T x_{0}\right) \ll c
$$

for all $m>n$. Then we get $d\left(T x_{n}, T x_{m}\right) \ll c$ for all $n>m$. Therefore, $\left\{T x_{n}\right\}$ is a Cauchy sequence in $(X, d)$. As $X$ is complete, there exists $z \in X$ such that $\lim _{n \rightarrow \infty} T x_{n}=z$.

Since $T$ is subsequentially convergent, $\left\{x_{n}\right\}$ has a convergent subsequence $\left\{x_{m}\right\}$ such that $\lim _{m \rightarrow \infty} x_{m}=u$. As $T$ is continuous $\lim _{m \rightarrow \infty} T x_{m}=T u$.

By the uniqueness of the limit, $z=T u$. Since $f$ and $g$ are continuous, $\lim _{m \rightarrow \infty} g x_{m}=g u$ and $\lim _{m \rightarrow \infty} f x_{m}=f u$.

The rest of the proof is similar to the proof of Theorem 2.1.

\section{References}

[1] L.G. Huang, X.Zhang, Cone Metric Spaces and Fixed Point Theorems of contractive mappings, J. Math.Anal. Appl., 332, (2007), 1468-1476.

[2] A. Beiranvand, S. Moradi, M. Omid and H. Pazandeh, Two Fixed Point Theorems for Special Mappings, arxiv:0903.1504v1[math.FA],(2009).

[3] M.Ozturk, M. Basarir, On Some Common Fixed Point Theorems for fcontraction Mappings in Cone Metric Spaces, Int. J. of Math. Analysis, Vol.5, 2011,no.3,119-127.

[4] M. Abbas, B.E.Rhoades, Fixed and Periodic Point Results in Cone Metric Spaces, Applied Math. Letters, 22(4)(2009),511-515.

[5] J. Morales E. Rojas, Cone Metric Spaces and Fixed Point Theorems for T-Kannan Contractive Mappings, arxiv:0907.3949v1[math.FA],(2009).

[6] J. Morales E. Rojas, T-Zamfirescu and T-Weak Contraction Mappings on Cone Metric Spaces arxiv:0909.1255v1[math.FA],(2009).

[7] J.Chen,Z.Li,Common Fixed Points for Banach Operator Pairs in Best Approximation, J. Math Anal.Appl.336(2007),1466-1475.

[8] R. Sumitra, V.R. Uthariaraj, R. Hemavathy, Common Fixed Point Theorem for T-Hardy-Rogers Contraction Mapping in a Cone Metric Space, International Mathematical Forum 5 (2010), 1495-1506. 
[9] P.V. Subrahmanyam, Remarks on Some Fixed Point Theorems Related to Banach's Contraction Principle, J. Math. Phys.Sci.,8(1974)445-457.

[10] I. Beg, A. Azam, M. Arshad, Common Fixed Points For Maps on Topological Vector Space Valued Cone Metric Spaces, International Journal of Mathematics and Mathematical Sciences, (2009), 1-8.

[11] D. Ilic, V. Rakocevic, Common Fixed Points for Maps on Cone Metric Space, J. Math. Anal. Appl., 341(2008),876-882.

[12] G.S. Jeong, B.E. Rhoades, Maps For Which $\mathrm{F}(\mathrm{T})=\mathrm{F}\left(\mathrm{T}^{n}\right)$, Fixed Point Theory and Applications, 6(2004)71-105.

[13] A.K.Dubey and A. Narayan, Cone Metric Spaces and Fixed Point Theorems for Pair of contractive maps, Mathematica Aeterna, Vol.2,2012,no.10,839-845.

[14] A.K Dubey Rita Shukla, R.P. Dubey, An Extension of the Paper "Cone Metric Spaces and Fixed Point Theorems of Contractive Mappings", Int. J. of Applied Mathematical Research, 2(1), (2013), 84-90.

[15] B.E.Rhoades, A comparison of various definitions of contractive mappings, Trans. Amer. Math.Soc.,226(1977),257-290.

[16] S. Reich, Some remarks concerning contraction mappings, Canad. Math. Bull., 14, (1971),121-124. 
